\title{
Application of transverse tibial bone transport and microcirculation reconstruction in the treatment of diabetic foot ulcer: a case report
}

\author{
Xuesong Zhang ${ }^{1,2}$, Tingting Dong ${ }^{3}$, Shaoping $\mathrm{Yao}^{2}$, Sheng $\mathrm{Lu}^{2}$, Weichao Li ${ }^{1,2} \wedge$ \\ ${ }^{1}$ Faculty of Medical Science, Kunming University of Science and Technology, Kunming, China; ${ }^{2}$ Department of Orthopedic Surgery, The First \\ People's Hospital of Yunnan Province, Affiliated Hospital of Kunming University of Science and Technology, Kunming, China; ${ }^{3}$ Department of \\ Rehabilitation Medicine, The First People's Hospital of Yunnan Province, Affiliated Hospital of Kunming University of Science and Technology, \\ Kunming, China \\ Correspondence to: Weichao Li. Faculty of Medical Science, Kunming University of Science and Technology, No. 727, Jingming South Road, \\ Chenggong District, Kunming 650500, China. Email: liweichao0394@sina.com.
}

\begin{abstract}
Diabetic foot ulcer (DFU) is a common complication in the advanced stages of diabetes mellitus. DFU in these individuals cannot heal properly over time due to microcirculatory changes that hinder and stagnate the healing process. There is a wide range of therapeutic strategies for DFU, but only minimal efficacy has been found in limited published studies. Transverse tibial bone transport (TTBT) is a new strategy for DFU, which based on Ilizarov technology. We present a case of a 45 -year-old female with longstanding type 2 diabetes complicated with slowly expanding ulceration to her right foot. According to the symptoms, signs, and medical history, she was diagnosed as DFU with osteomyelitis. After sufficient preoperative preparation, including tight blood glucose control, wound dressing, and anti-infection therapy, the ulcer was treated with Ilizarov TTBT. Under these interventions, the ulcer gradually improved. The patient's foot ulcer was completely healed seven months after surgery, and foot function was well preserved. No complications were observed during the follow-up. For patients with refractory DFU, TTBT should be considered a promising treatment option for maintaining the foot's shape and function. The present study's findings indicate that further studies should focus on the mechanism of microcirculation reconstruction for the treatment of DFU.
\end{abstract}

Keywords: Diabetic foot ulcer (DFU); transverse tibial bone transport (TTBT); microcirculation; case report

Submitted Oct 17, 2020. Accepted for publication Feb 02, 2021.

doi: 10.21037/apm-20-2053

View this article at: http://dx.doi.org/10.21037/apm-20-2053

\section{Introduction}

Diabetic foot ulcer (DFU) is one of the most serious complications of diabetes mellitus (1). In diabetes with concomitant peripheral arterial disease or poor blood sugar control, localized infection, peripheral neuropathy or foot deformities, foot ischemia or neuropathy are likely to occur, eventually resulting in foot ulcers, dysfunction, and paresthesia $(1,2)$. In some cases, patients with severe diabetes may even develop foot osteomyelitis or require lower limb amputation (3).

Many therapeutic strategies, such as topical wound oxygen therapy, shock wave, and collagen dressing, have been used to treat DFU, but their effectiveness is not significant. Transverse tibial bone transport (TTBT) is a new treatment for DFU based on Ilizarov technology. The Ilizarov technique, a biological theory put forward

^ ORCID: 0000-0001-9036-9028. 

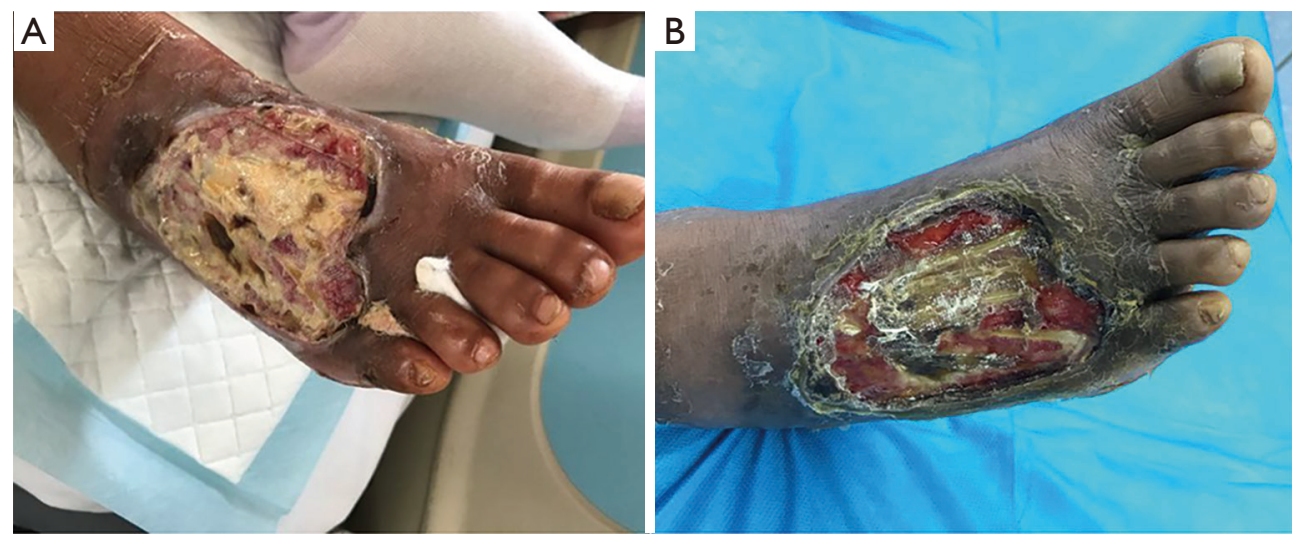

Figure 1 Changes in the ulceration at admission and at 2 weeks after admission. (A) On admission, there was a lot of exudation and pus in the ulcer. (B) Two weeks after admission, the pus in the ulcer had decreased.

Table 1 Patient characteristic

\begin{tabular}{|c|c|c|c|c|c|c|c|}
\hline Gender & $\begin{array}{l}\text { Age } \\
\text { (years) }\end{array}$ & $\begin{array}{c}\text { BMI } \\
\left(\mathrm{kg} / \mathrm{m}^{2}\right)\end{array}$ & $\begin{array}{l}\text { Fasting blood } \\
\text { sugar (mmol/L) }\end{array}$ & $\begin{array}{c}\text { Basic } \\
\text { disease }\end{array}$ & Complication & $\begin{array}{l}\text { Concomitant } \\
\text { medications }\end{array}$ & $\begin{array}{c}\text { Blood sugar control } \\
\text { before admission }\end{array}$ \\
\hline Female & 45 & 19.4 & $13.4-16.8$ & $\begin{array}{c}\text { Type } 2 \text { diabetes; } \\
\text { hypertension }\end{array}$ & $\begin{array}{l}\text { Osteomyelitis; foot } \\
\text { ulcer }\end{array}$ & $\begin{array}{l}\text { Metformin; } \\
\text { Acarbose }\end{array}$ & Poor \\
\hline
\end{tabular}

by Professor Ilizarov (4), is a transverse distraction of the tibial osteotomy stump with an adjustable external fixator to provide continuous tension-stress to local bone tissue and soft tissue, which could stimulate the new growth of bone and adherent muscle fiber, vascular cell, and fascia. It has been reported that, under the guidance of the tensionstress rules of Ilizarov, TTBT can reconstruct blood circulation, and stimulate tissue regeneration and active growth by continuous tibia traction. The blood supply of the bone marrow cavity in the tibia is rich, quickly forming a microvascular system. In the present paper, we report a female with DFU treated by TTBT according to the Ilizarov technique. We found a few reported cases on TTBT in the treatment of DFU in our literature search. We present the following case in accordance with the CARE reporting checklist (available at http://dx.doi.org/10.21037/ apm-20-2053).

\section{Case presentation}

In 2018, a 45-year-old woman with type 2 diabetes for 16 years began to develop pea-sized nodules on the dorsum of her right foot, with local redness and itching. After the nodule was scratched, a yellowish fluid was observed. The skin of the foot's dorsum then began to break, and the skin damage gradually increased, accompanied by pus. Physical examination showed that the skin of the dorsum of the right foot was ulcerated, and the tendon and periosteum were exposed, with a large amount of yellow and white foulsmelling pus and obvious redness and swelling around the defective skin (Figure 1A). The patient's superficial sensation decreased significantly, and there was an obvious obstacle to the flexion and extension of her right toes.

After admission, the following laboratory results were obtained: white blood cell $6.76 \times 10^{9} / \mathrm{L}$, the absolute value of neutrophils $3.77 \times 10^{9} / \mathrm{L}$, hemoglobin $112 \mathrm{~g} / \mathrm{L}, \mathrm{C}$-reactive protein $15.20 \mathrm{mg} / \mathrm{L}$, glycated haemoglobin $86 \mathrm{mmol} / \mathrm{mol}$ $(10.5 \%)$, and erythrocyte sedimentation rate $95 \mathrm{~mm} / \mathrm{h}$. Bacterial culture was negative. Imaging findings showed irregular bone morphology and osteomyelitis at the distal edge of the 5 th toe of the right foot. According to clinical manifestations and her long-term history of diabetes, the patient was diagnosed as DFU with toe osteomyelitis (Table 1). After 2 weeks of tight blood control, wound dressing and anti-infection therapy (Figure 1B), the ulcer was treated with Ilizarov TTBT (Table 2).

Under general anesthesia, with the patient in the supine position, 2 external fixation half-pins of suitable length were 
Table 2 Ulcer management during the patient's treatment

\begin{tabular}{lll}
\hline & Measures & Usage and dosage \\
\hline Blood sugar control & Insulin aspart; insulin detemir & $\begin{array}{l}\text { Before breakfast (18 U), lunch (16 U), and dinner (18 U), subcutaneous } \\
\text { injection, ter in die; bedtime (20 U), subcutaneous injection, quaque nocte }\end{array}$ \\
Wound management & Dressing with insulin-soaked gauze & External application, quaque 12 hour \\
Anti-infection therapy & Cefoxitin sodium & $2 \mathrm{~g}$, intravenous drip, bis in die \\
\hline
\end{tabular}
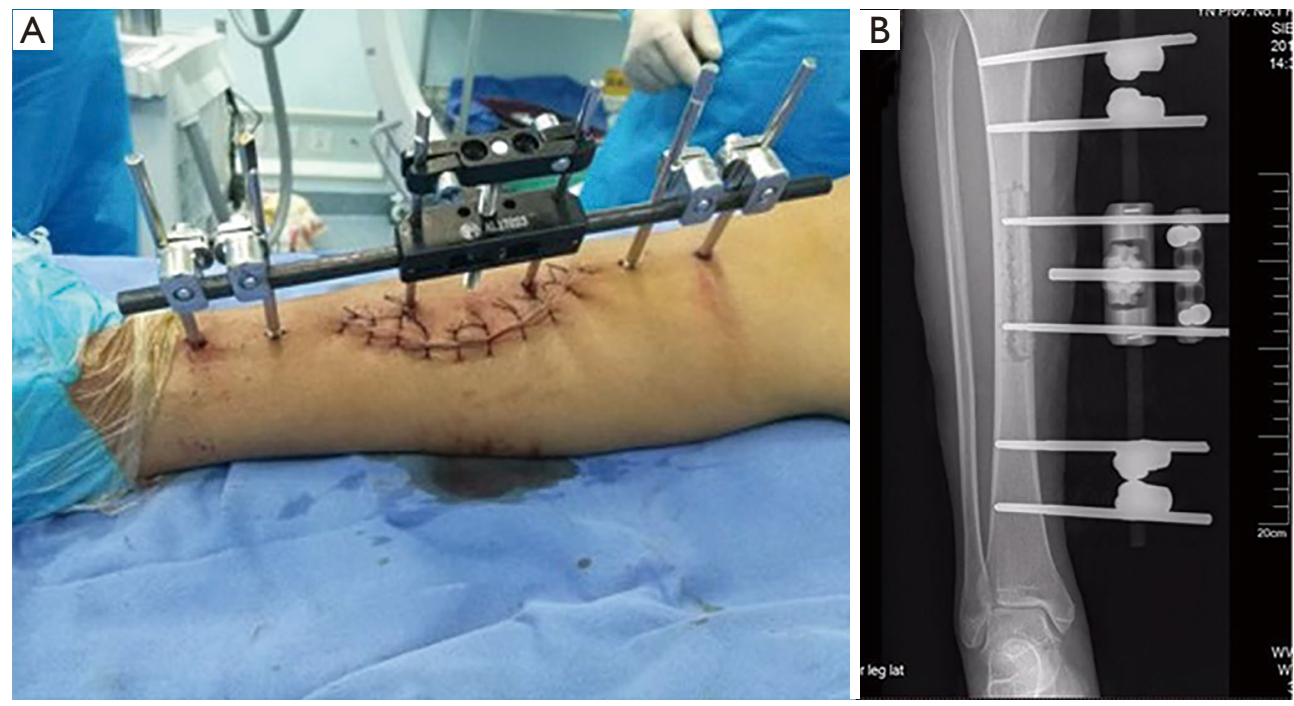

Figure 2 Transverse tibial bone transport was performed on the patient. (A) External fixator was fixed to the medial side of the tibia intraoperatively. (B) Postoperative X-ray image of the right tibia at the anteroposterior position.

placed on the medial $4 \mathrm{~cm}$ above the ankle joint along the right tibial axis; the other 2 fixation half-pins were placed on the medial $4 \mathrm{~cm}$ below the tibial tubercle. A $15-\mathrm{cm}$ anteromedial curved incision was made in the middle and lower tibia. After the separation of the subcutaneous tissue, a $7 \mathrm{~cm} \times 4 \mathrm{~cm}$ osteotomy window was created at the incision. According to the planned osteotomy range, the bone cortex was cut with a swing saw to form a movable bone flap. Two half-pins in the center of the external fixator were inserted into the upper and lower parts of the bone flap to laterally move the osteotomy. After the angle was adjusted properly under the supervision of the $\mathrm{C}$-arm, the external fixing bracket with 2 lateral tractors was installed on the 4 external fixation pins, and the tractors were fixed to the traction pins (Figure 2A). An X-ray showed that the screw penetrated 2 layers of bone cortex, and the position of the external fixator was satisfactory (Figure $2 B$ ). The operation went well, and there were no intraoperative complications. Purulent secretions and necrotic tissue in the foot ulcer were properly cleaned and covered with sterile dressings.

After the operation, the dressing was changed regularly, the anti-infective drugs were used regularly, blood sugar was controlled strictly, and the patient's foot function was strengthened through exercises. After these interventions, the bone transport operation was started on the 7 th postoperative day. The osteotomy was pulled laterally $1 \mathrm{~mm}$ on every day and stopped after 14 days, and then pushed back for 14 days. The above process was repeated 3 times, and the external fixator, which was used for 7 months in total, was removed after the fracture healed. The patient's symptoms alleviated, and the ulcer in the right foot healed gradually after the operation. The ulcer began to shrink, and the dorsal foot skin temperature improved significantly from the 1 st week to the 3 rd week, postoperatively (Figure $3 A, B, C$ ). After discharge, we arranged a 24-month follow-up (Table 3). The ulcer in the patient's right foot improved, and the redness and swelling subsided significantly from the 12th week to the 16 th week, 

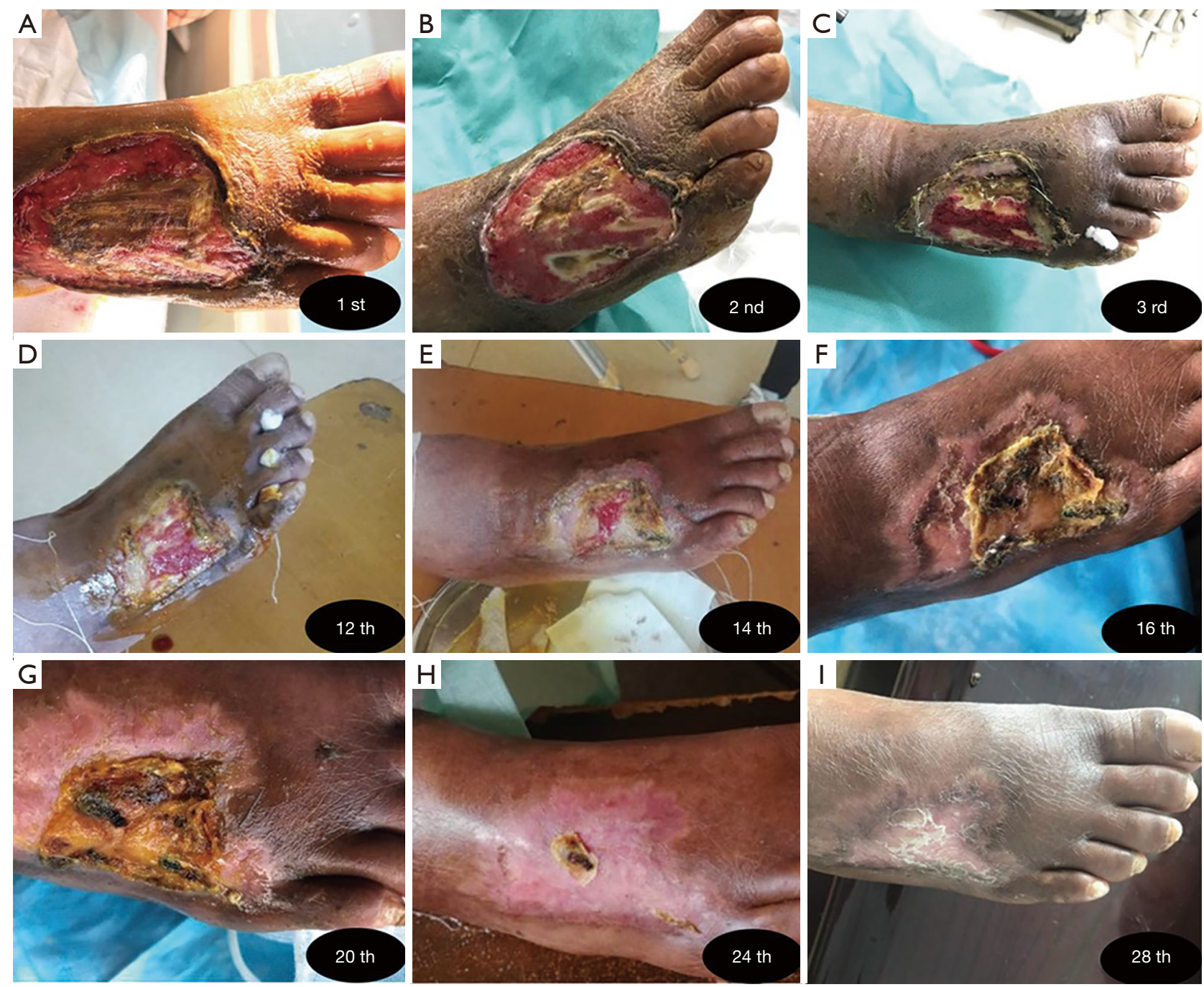

Figure 3 Changes in the ulceration from the 1 st to the 28th week, postoperatively. (A) At 1 week postoperatively, the effusion had significantly decreased. (B) At 2 weeks postoperatively, granulation tissue had appeared. (C) At 3 weeks postoperatively, the ulcer area had significantly reduced. (D) At 12 weeks postoperatively, cutaneous sensation had improved significantly. (E) At 14 weeks postoperatively, the depth of the ulcer was significantly shallow. (F) At 16 weeks postoperatively, the ulcer had scabbed over. (G) At 20 weeks postoperatively, the scab was replaced by new skin tissue. $(\mathrm{H})$ At 24 weeks postoperatively, the scab came off. (I) At 28 weeks postoperatively, the ulcer had completely healed.

postoperatively (Figure 3D,E,F). From the 20th week to the 28th week, postoperatively, the foot ulcer had healed completely, and foot function had recovery (Figure 3G,H,I). No complications were reported during the follow-up.

The study was conducted in accordance with the Declaration of Helsinki (as revised in 2013). Written informed consent was obtained from the patient for publication of this case report and any accompanying images.

\section{Discussion}

With the increasing number of people with diabetes, foot ulcers are increasingly common. It places a considerable burden on people with diabetes and society in general and increases the morbidity, burden of health care, and mortality $(1,5)$. People with DFU have a 2.5 times higher risk of death within 5 years than those without (6). It is estimated that the incidence of ulcers, infections, and 
Table 3 Wound baseline characteristics of the patient postoperatively

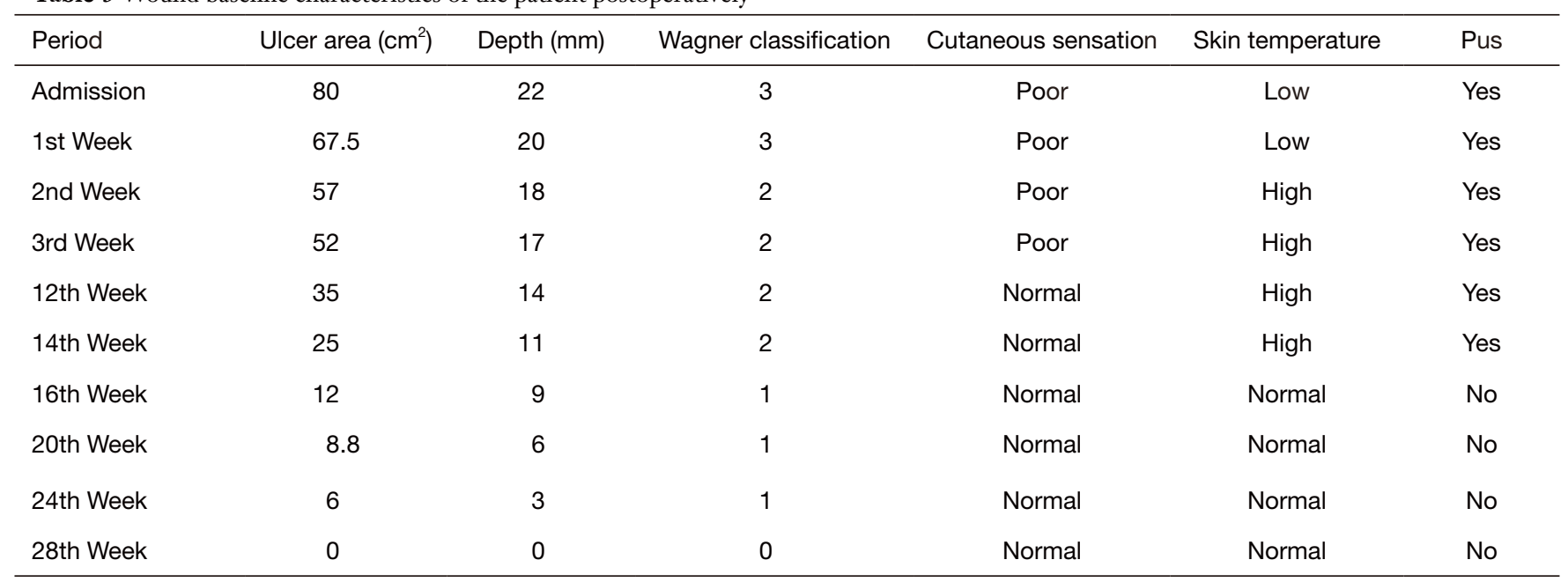

amputations among people with diabetes is $68 \%, 36 \%$, and $6 \%$, respectively (7). Our patient was diagnosed as DFU with osteomyelitis of the phalangeal bone of the right foot in the present case. Laboratory results showed that the erythrocyte sedimentation rate and $\mathrm{C}$-reactive protein were significantly increased, but the bacterial culture was negative. As the most common pathogen of diabetic foot is Staphylococcus aureus, we used pentahydrate cefazolin to conduct prophylactic antibacterial treatment on the patient during hospitalization $(5,8)$.

TTBT is a novel method for the treatment of DFU. At present, there are few reports on its mechanism. The distraction histogenesis principle is that a certain tension will be generated when the biological tissue is pulled slowly, stimulating neovascularization and increasing perfusion to the bone and surrounding soft tissues. TTBT can upregulate the expression of vascular endothelial growth factors, which can stimulate collagenase production, effectively inhibiting the synthesis of hydroxyproline and promoting vascular regeneration $(9,10)$. Zeng et al. used computed tomography to observe blood perfusion after TTBT and found that TTBT could increase plantar tissue perfusion, which may be related to increased functional capillaries opening (11). In our study, the foot ulcer healed completely over time, and lower limb temperature and pain improved significantly. This suggests that lower limb revascularization was successful. Chen et al. reported that TTBT can effectively reduce amputation and recurrence rates and that the complications of TTBT are minimal (12). Using a transverse distraction model of the canine tibia, Matsuyama et al. found that the average vascular volume ratio in the stretch area was more than 3 times that of the intact contralateral tibia (13). Therefore, TTBT has the advantages of less trauma, lower cost, faster recovery after an operation, lower amputation rate, effectively relieving pain, improving skin tone, and reducing local swelling.

In addition to surgery, we also taught the patient about proper foot care, such as having regular foot checkups, controlling her blood sugar, avoiding infections and injuries, wearing comfortable footwear of the right size, and avoiding long-time standing, which are effective interventions to promote foot ulcer healing $(1,14)$. Based on her age, physical condition, the degree of DFU, and the severity of complications, we also provided the patient with individualized education, which could effectively reduce anxiety, enhance adherence to therapy, improve wound healing, and shorten the length of hospital stay.

However, the treatment of DFU is complicated. The curative effect of TTBT on diabetic foot is closely related to the cooperative treatment of vascular surgery, endocrinology, and nursing (15). The patient's foot had to be fixed to an external fixator for at least six months, so good compliance is also required. Some studies have found that the healing of ulcers is affected by factors, such as the site of osteotomy, method, waiting time, speed of distraction, the blood supply of surrounding tissue, and soft tissue condition (16); therefore, proper management of people with DFU by medical staff is particularly important.

Our study and operation have some limitations. We only researched 1 patient; therefore, the advantages and disadvantages of TTBT are limited to our patient. The effectiveness of TTBT in other lower extremity 
microvascular diseases, such as thromboangiitis obliterans and arteriosclerotic obliteration, is uncertain. Besides, patients with TTBT need to spend long periods to use external fixation, making them inconvenient in their treatment. More population-based trials are needed to demonstrate the safety and effectiveness of the procedure.

In conclusion, TTBT can promote vascular regeneration and tissue repair of the foot and accelerate ulcer healing, and appears to be an effective measure for the treatment of DFU.

\section{Acknowledgments}

The authors thank AME Editing Service for English editing.

Funding: This work was supported by the National Natural Science Foundation of China (Grant No.: 81860240) and the Talent Development Program of Yunnan Province (Grant No.: H-2018100).

\section{Footnote}

Reporting Checklist: The authors have completed the CARE reporting checklist. Available at http://dx.doi.org/10.21037/ apm-20-2053

Conflicts of Interest: All authors have completed the ICMJE uniform disclosure form (available at http://dx.doi. org/10.21037/apm-20-2053). The authors have no conflicts of interest to declare.

Ethical Statement: The authors are accountable for all aspects of the work in ensuring that questions related to the accuracy or integrity of any part of the work are appropriately investigated and resolved. The study was conducted in accordance with the Declaration of Helsinki (as revised in 2013). Written informed consent was obtained from the patient for publication of this case report and any accompanying images.

Open Access Statement: This is an Open Access article distributed in accordance with the Creative Commons Attribution-NonCommercial-NoDerivs 4.0 International License (CC BY-NC-ND 4.0), which permits the noncommercial replication and distribution of the article with the strict proviso that no changes or edits are made and the original work is properly cited (including links to both the formal publication through the relevant DOI and the license). See: https://creativecommons.org/licenses/by-nc-nd/4.0/.

\section{References}

1. Schaper NC, van Netten JJ, Apelqvist J, et al. Practical Guidelines on the prevention and management of diabetic foot disease (IWGDF 2019 update). Diabetes Metab Res Rev 2020;36:e3266.

2. Reiber GE, Vileikyte L, Boyko EJ, et al. Causal pathways for incident lower-extremity ulcers in patients with diabetes from two settings. Diabetes Care 1999;22:157-62.

3. Rayman G, Vas P, Dhatariya K, et al. Guidelines on use of interventions to enhance healing of chronic foot ulcers in diabetes (IWGDF 2019 update). Diabetes Metab Res Rev 2020;36:e3283.

4. Ilizarov GA. The tension-stress effect on the genesis and growth of tissues: Part II. The influence of the rate and frequency of distraction. Clin Orthop Relat Res 1989;239:263-85.

5. Chen SY, Giurini JM, Karchmer AW. Invasive Systemic Infection Following Hospital Treatment for Diabetic Foot Ulcer: Risk of Occurrence and Effect on Survival. Clin Infect Dis 2017;64:326-34.

6. Walsh JW, Hoffstad OJ, Sullivan MO, et al. Association of diabetic foot ulcer and death in a population-based cohort from the United Kingdom. Diabet Med 2016;33:1493-8.

7. Lavery LA, Armstrong DG, Wunderlich RP, et al. Diabetic foot syndrome: evaluating the prevalence and incidence of foot pathology in Mexican Americans and non-Hispanic whites from a diabetes disease management cohort. Diabetes Care 2003;26:1435-8.

8. Jneid J, Cassir N, Schuldiner S, et al. Exploring the Microbiota of Diabetic Foot Infections With Culturomics. Front Cell Infect Microbiol 2018;8:282.

9. Zuo Q, Gao F, Song H, et al. Application of Ilizarov transverse tibial bone transport and microcirculation reconstruction in the treatment of chronic ischemic diseases in lower limbs. Exp Ther Med 2018;16:1355-9.

10. Zigdon-Giladi H, Khutaba A, Elimelech R, et al. VEGF release from a polymeric nanofiber scaffold for improved angiogenesis. J Biomed Mater Res A 2017;105:2712-21.

11. Zeng Z, Dong Y, Hua Q, et al. Computed tomography perfusion study evaluating the curative effect of tibial transverse transport in patients with severe diabetic foot. J Orthop Translat 2019;19:133-42.

12. Chen Y, Kuang X, Zhou J, et al. Proximal Tibial Cortex Transverse Distraction Facilitating Healing and Limb Salvage in Severe and Recalcitrant Diabetic Foot Ulcers. Clin Orthop Relat Res 2020;478:836-51.

13. Matsuyama J, Ohnishi I, Kageyama T, et al. Osteogenesis 
and angiogenesis in regenerating bone during transverse distraction: quantitative evaluation using a canine model. Clin Orthop Relat Res 2005;433:243-50.

14. Singh N, Armstrong DG, Lipsky BA. Preventing foot ulcers in patients with diabetes. JAMA 2005;293: 217-228.

15. Ahmad Sharoni SK, Abdul Rahman H, Minhat HS, et al. The effects of self-efficacy enhancing program on foot self- care behavior of older adults with diabetes: A randomized controlled trial in elderly care facility, Peninsular Malaysia. Plos One 2018;13:e0192417.

16. Tsuchiya H, Sakurakichi K, Yamashiro T, et al. Bone transport with frozen devitalized bone: an experimental study using rabbits and a clinical application. J Orthop Sci 2004;9:619-24.

Cite this article as: Zhang X, Dong T, Yao S, Lu S, Li W. Application of transverse tibial bone transport and microcirculation reconstruction in the treatment of diabetic foot ulcer: a case report. Ann Palliat Med 2021;10(7):8358-8364. doi: 10.21037/apm-20-2053 